FERMILAB-TM-1811

\title{
PS1 Satellite Refrigerator Heat Exchanger: Failure of the LN2 Heat Exchanger to Low Pressure Helium
}

\author{
Bruce Squires \\ Fermi National Accelerator Laboratory \\ P.O. Box 500, Batavia, Illinois 60510
}

November 1992 


\section{Disclaimer}

This report was prepared as an account of work sponsored by an agency of the United States Government. Neither the United States Government nor any agency thereof, nor any of their employees, makes any warranty, express or implied, or assumes any legal liability or responsibility for the accuracy, completeness, or usefulness of any information, apparatus, product, or process disclosed, or represents that its use would not infringe privately owned rights. Reference herein to any specific commercial product, process, or service by trade name, trademark, manufacturer, or otherwise, does not necessarily constitute or imply its endorsement, recommendation, or favoring by the United States Government or any agency thereof. The views and opinions of authors expressed herein do not necessarily state or reflect those of the United States Government or any agency thereof. 


\title{
PS1 SATELLITE REFRIGERATOR HEAT EXCHANGER: FAILURE OF THE LN2 HEAT EXCHANGER TO LOW PRESSURE HELIUM
}

\author{
Bruce Squires \\ Fermi National Accelerator Laboratory \\ Research Division Mechanical Support Department
}

October 9,1992

\section{INTRODUCTION}

The PS1 heat exchanger is one of three prototype heat exchangers built by Atomic Welders before Meyer was given the contract to build the Satellite Refrigerator Heat Exchanger components. This heat exchanger was first put into operation in July 1983. In November 1991, this heat exchanger experienced a failure in the shell of heat exchanger 1 causing nitrogen to contaminate the helium in the refrigerator. The resulting contamination plugged heat exchanger 3. The break occurred at a weld that connects a 0.25 inch thick ring to heat exchanger 1 . See figure 1 for the location of the failure. The failure appears to be a fatigue of the shell due to temperature oscillations. The flow rate through the break was measured to be $1.0 \mathrm{scfm}$ for a pressure drop over the crack of $50 \mathrm{psi}$. An ANSYS analysis of the failure area indicates that the stress would be $83,000 \mathrm{psi}$ if the metal did not yield. This is based on cooling down the shell to $80 \mathrm{~K}$ from $300 \mathrm{~K}$ with the shell side helium on the outside of the shell at $300 \mathrm{~K}$. This is the largest change in temperature that occurs during operation. During normal operations, the temperature swings are not nearly this large, however temperatures down to $80 \mathrm{~K}$ are not unusual (LN2 overflowing pot). The highest temperatures are typically $260 \mathrm{~K}$. The analysis makes no attempt to estimate the stress concentration factor at this weld but there is no doubt that it is greater than 1. No estimate as to the number of cycles to cause failure was calculated nor any estimate as to the actual number of cycles was made. 


\section{ANALYSIS OF FAILURE AREA}

ANSYS was used to analyze the failure area of heat exchanger 1. For this analysis, both the maximum-shear criterion (Coulomb) and maximum-distortion-energy criterion (von Mises) were considered in determining the maximum stress at the failure area. For the cases considered while performing the analyses, the maximum-shear theory predicted higher stresses and was used to form the conclusions made in this document.

Figure 2 shows the dimensions used in the ANSYS analysis of the failure area. The thin gap was approximately 1/32". Upon removing the ring, it was apparent that the weld did not penetrate into the gap; only into the ring and the shell. Therefore, the analytical model has a gap of zero thickness with a length of $1 / 4 "$. The other analysis parameters are as follows:

- The side of the ring which faces the 8 " pipe is treated as perfectly insulated and the other face has convection with the shell side helium flow

- The $8^{\prime \prime}$ pipe is at a constant temperature of $80^{\circ} \mathrm{F}(300 \mathrm{~K})$

- The 6-3/16" OD shell of heat exchanger 1 is at a constant temperature of $-316^{\circ} \mathrm{F}(80 \mathrm{~K})$

The effect of changing from forced convection to no convection on the one face of the ring was only about $3 \mathrm{ksi}$ at the point of maximum stress.

Figure 3 shows the temperature distribution along the ring. The stresses created by this distribution are shown in figure 4. The two locations of highest stress are under the ring on the shell of heat exchanger 1. The first is on the inside of the shell and the other is in the area where the cracks were found near the weld. The axial principle stresses are plotted in figure 5. This clearly shows that the high stress area on the inside of the shell is compressive and that the area near the weld is tensive. The radial principle stresses are given in figure 6 . When considering that the stress concentration factor in the region at the weld is greater than 1 , it appears that large temperature swings at the cold end of this ring contributed to the failure of this shell. Most of the heat exchangers in use do not typically see this large of temperature swings, however they have had narrower temperature swings with the warm end of the ring closer to $273 \mathrm{~K}$ and the cold end changing anywhere from $80 \mathrm{~K}$ to $250 \mathrm{~K}$, depending on the demand on the refrigerator and on how well the liquid nitrogen controller works.

In order to determine the allowable temperature swings (those that cause stresses to remain less than yield), a few temperature ranges were calculated. The stresses at the ring weld approach $32,000 \mathrm{psi}$ when the temperature is dropped from $300 \mathrm{~K}$ to $230 \mathrm{~K}$ at the ring during cooldown with the helium shell flow at $300 \mathrm{~K}$. If the shell flow is $225 \mathrm{~K}$, a shell temperature of 
$150 \mathrm{~K}$ will cause a stress of $30,500 \mathrm{psi}$ at the weld. This indicates that a temperature difference over the ring of approximately $70 \mathrm{~K}$ will not cause yielding in the shell of the heat exchanger. Calculations performed at intermediate temperature ranges support this approximation. Based on this information, changes in temperature on the cold end of the ring should be controlled to avoid temperature swings greater than $70 \mathrm{~K}$ in order to increase the lifetime of this weld.

For detailed drawings on heat exchanger 1 and the surrounding heat exchanger 2 , refer to drawings 9110-MD-129233, 9110-MD-129234, and 9110-ME-129240.

\section{REASSEMBLY OF HEAT EXCHANGER}

In order to prevent another failure in the same area, three fixes were considered: a) making the ring thinner, b) not welding the ring to heat exchanger 1, and c) adding a "pantleg" extension to the ring. The first case is over stressed and the second allows more flow to bypass heat exchanger 2 than we determined to be acceptable. The third case, shown in figure 7 , reduces the stresses to less than the maximum allowable stress that is called out by the ASME Boiler and Pressure Vessel Code for 304 stainless steel (18,800 psi).

Figure 8 gives the dimensions of the modification to the heat exchanger. The stresses for this configuration were calculated for two levels of convection from the pantleg and the ring. The first for free convection and the other for forced convection. Each convection case led to high stresses in different areas. All other parameters of the analysis were performed for the same conditions as the original analysis. Figure 9 is for the free convection case showing the region of maximum stress $(15,000 \mathrm{psi})$ on the pantleg near the narrow ring on the shell of heat exchanger 1. The axial stresses are given in figure 10 and the radial stresses are in figure 11 . These figures confirm that the stresses for this case are acceptable. Figure 12 is for the forced convection case showing the highest stress (16,600 psi) at the warm end of the 1/4" ring. Even though this is the location of the highest stress by the maximum shear criterion, the highest axial stress shown in figure 13 and highest radial stress shown in figure 14 are at the same locations as the free convection case.

The PS1 heat exchanger has been modified based on this analysis. For details on the modifications, refer to drawing ME-194492. 


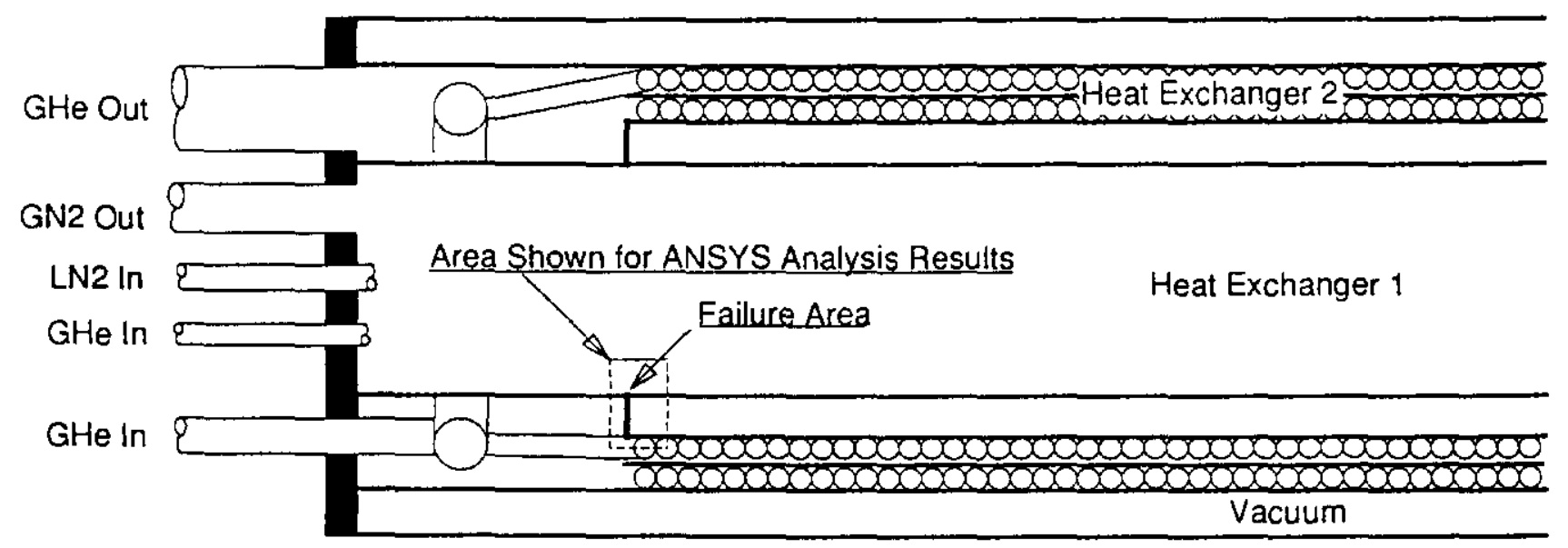

Figure 1. Simplified sketch of the warm end of the Satellite

Refrigerator Heat Exchanger indicating the failure area.

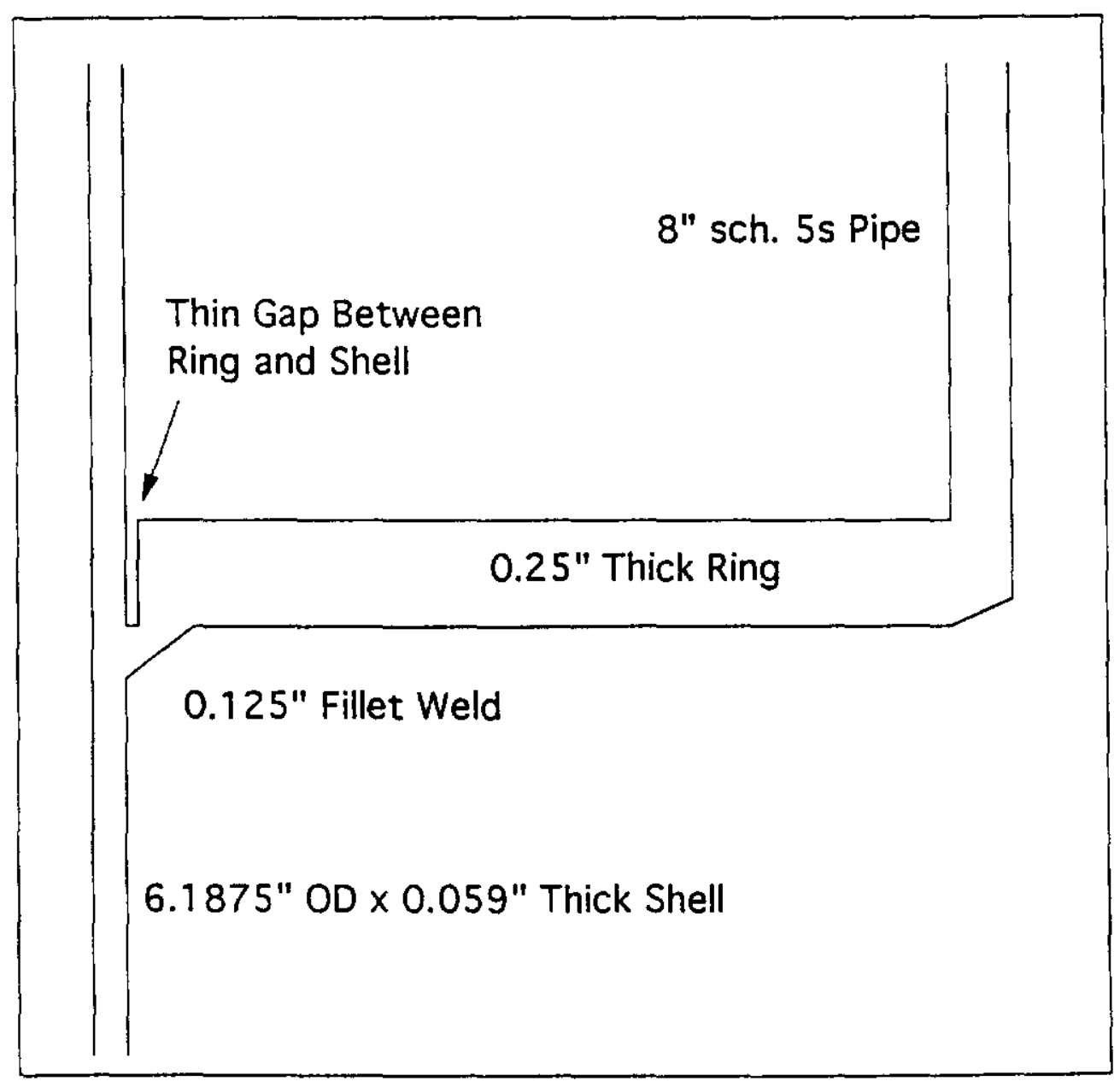

Figure 2. Dimensions used for the ANSYS analysis of the failure area. 


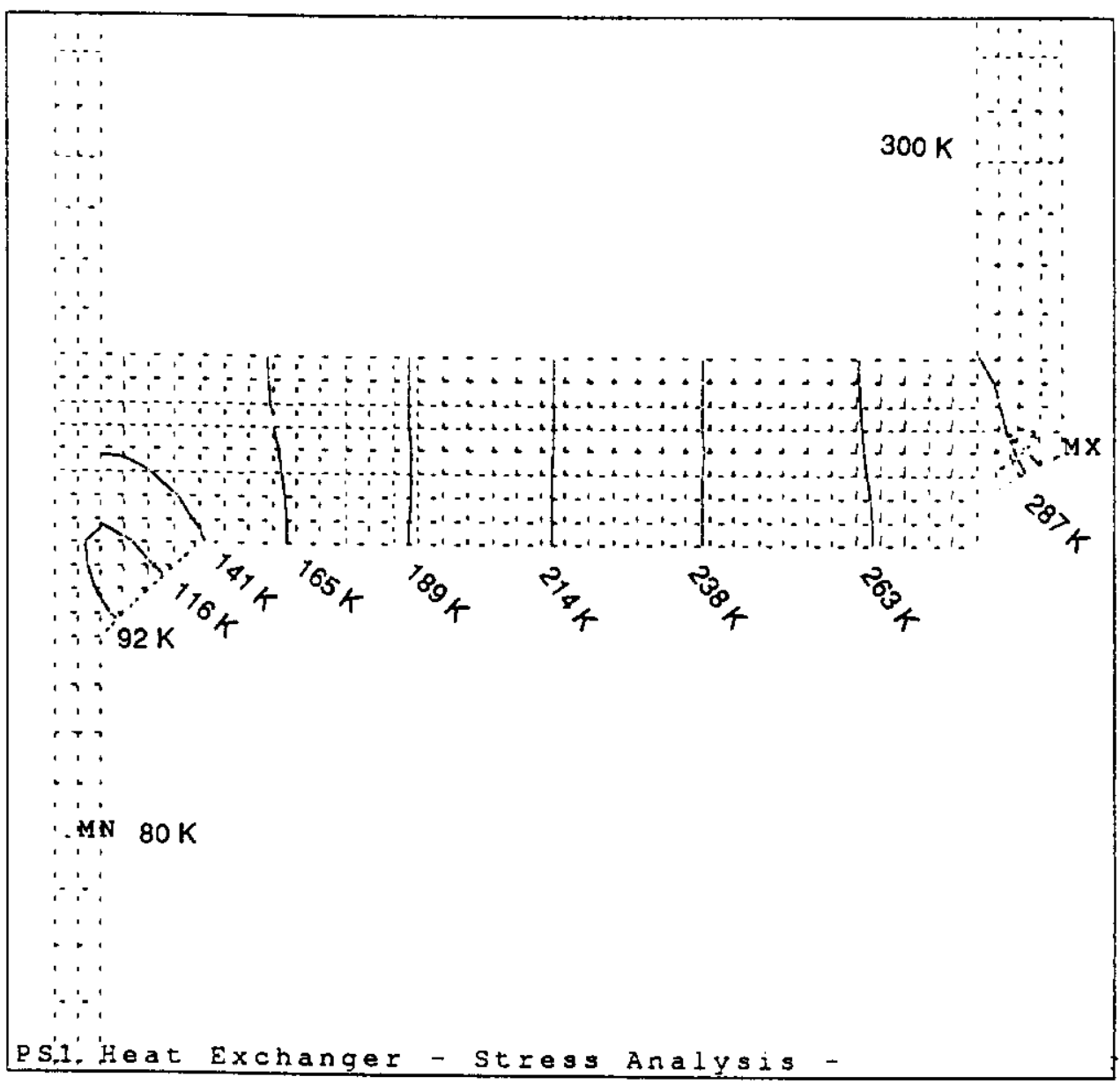

Figure 3. Temperature distribution derived from the ANSYS analysis of the failure area. 


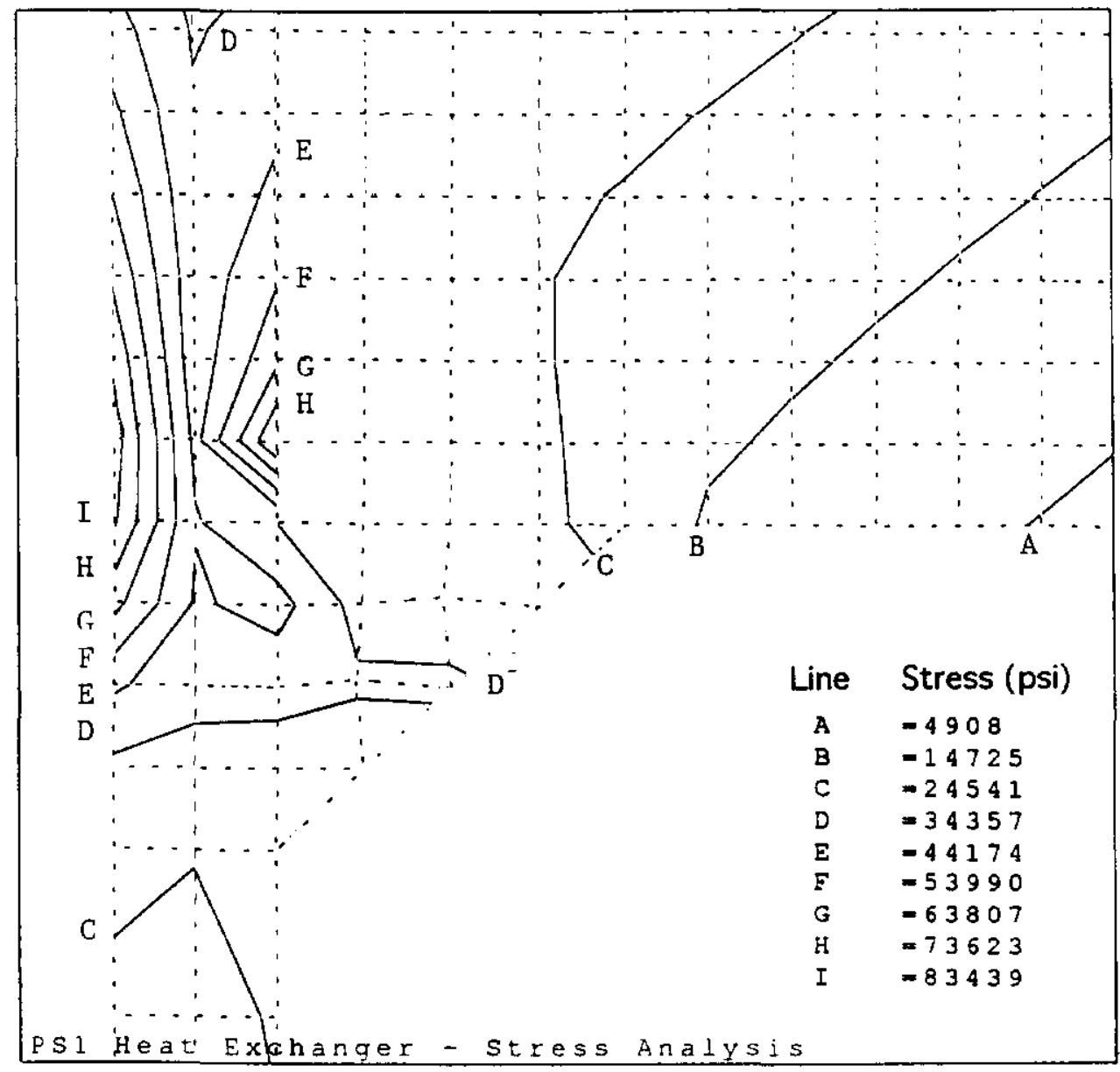

Figure 4. Stress distribution derived from the ANSYS analysis of the failure area (maximum-shear criterion).

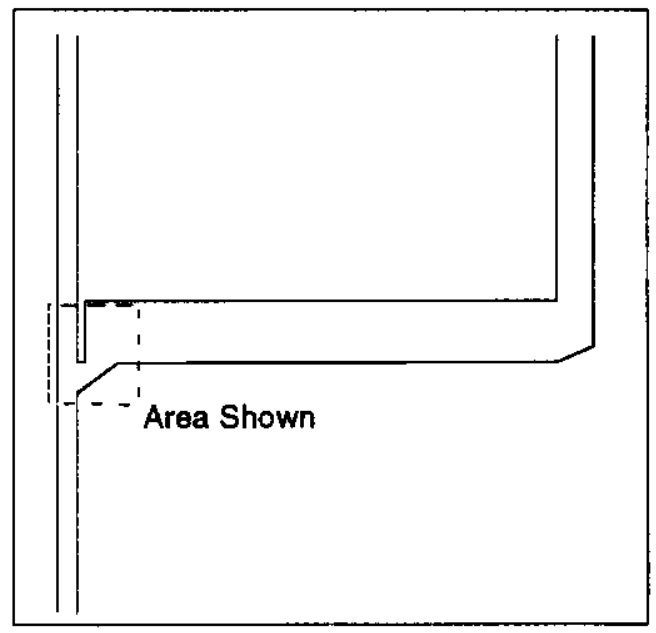




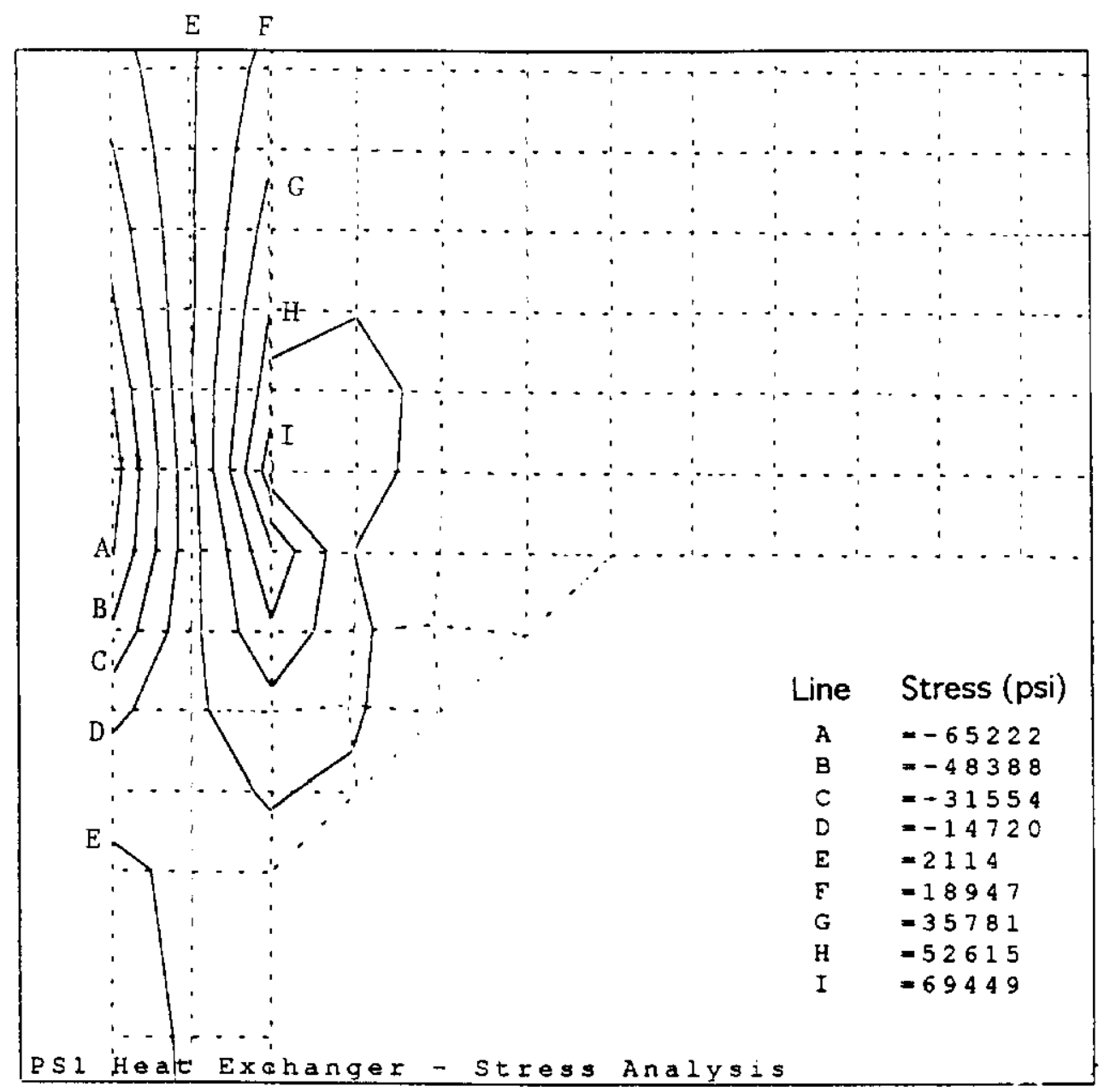

Figure 5. Axial component stresses derived from the ANSYS analysis of the failure area.

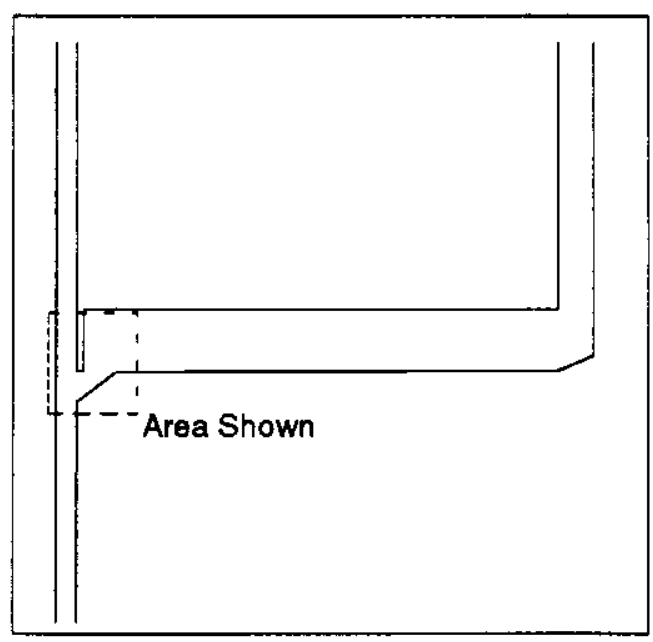




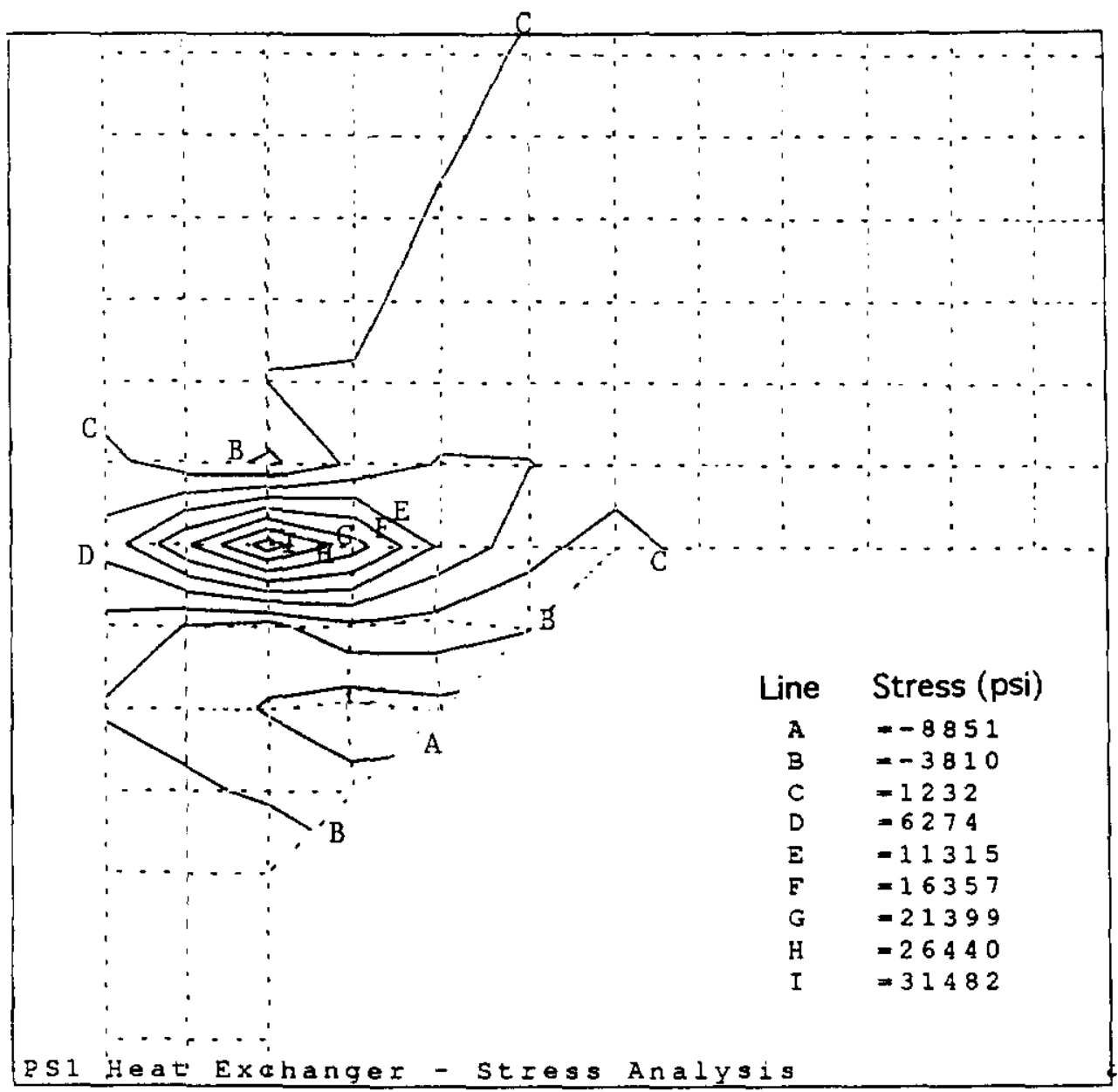

Figure 6. Radial component stresses derived from the ANSYS analysis of the failure area.

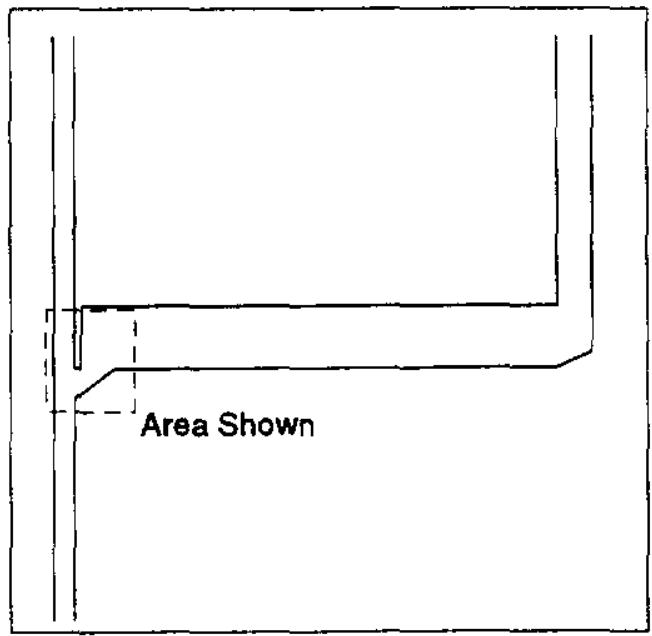




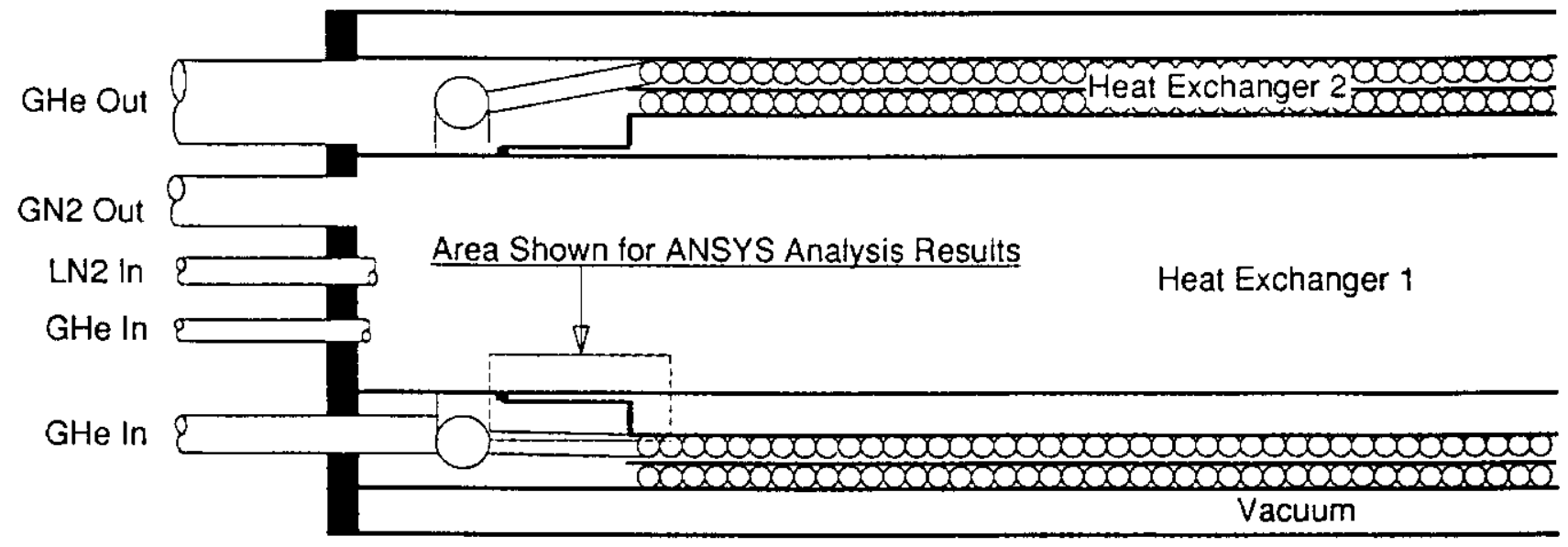

Figure 7. Simplified sketch of the warm end of the Satellite Refrigerator Heat Exchanger showing the modification analyzed with ANSYS.

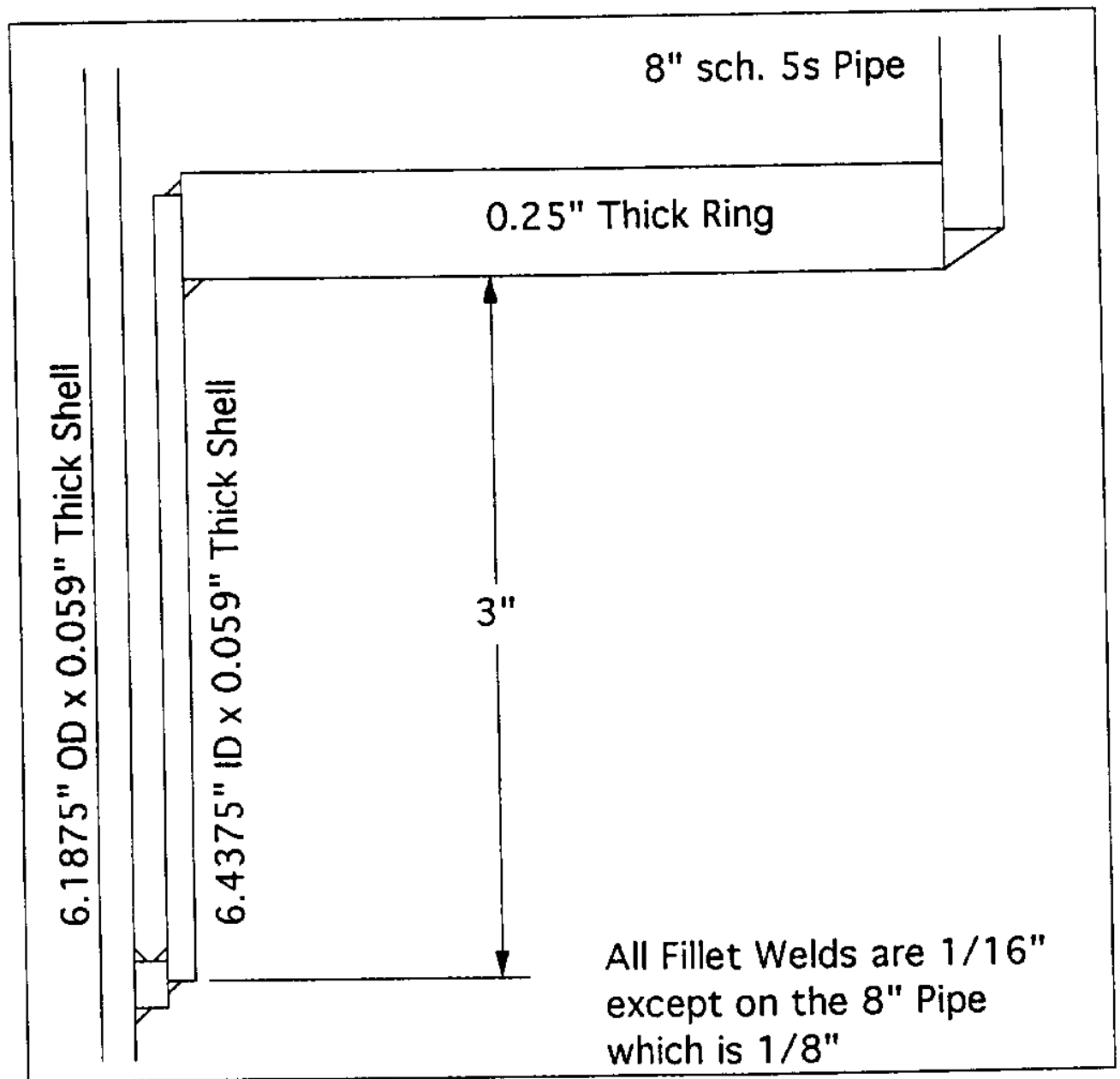

Figure 8. Dimensions of the modification to the heat exchanger. 
E D C C D

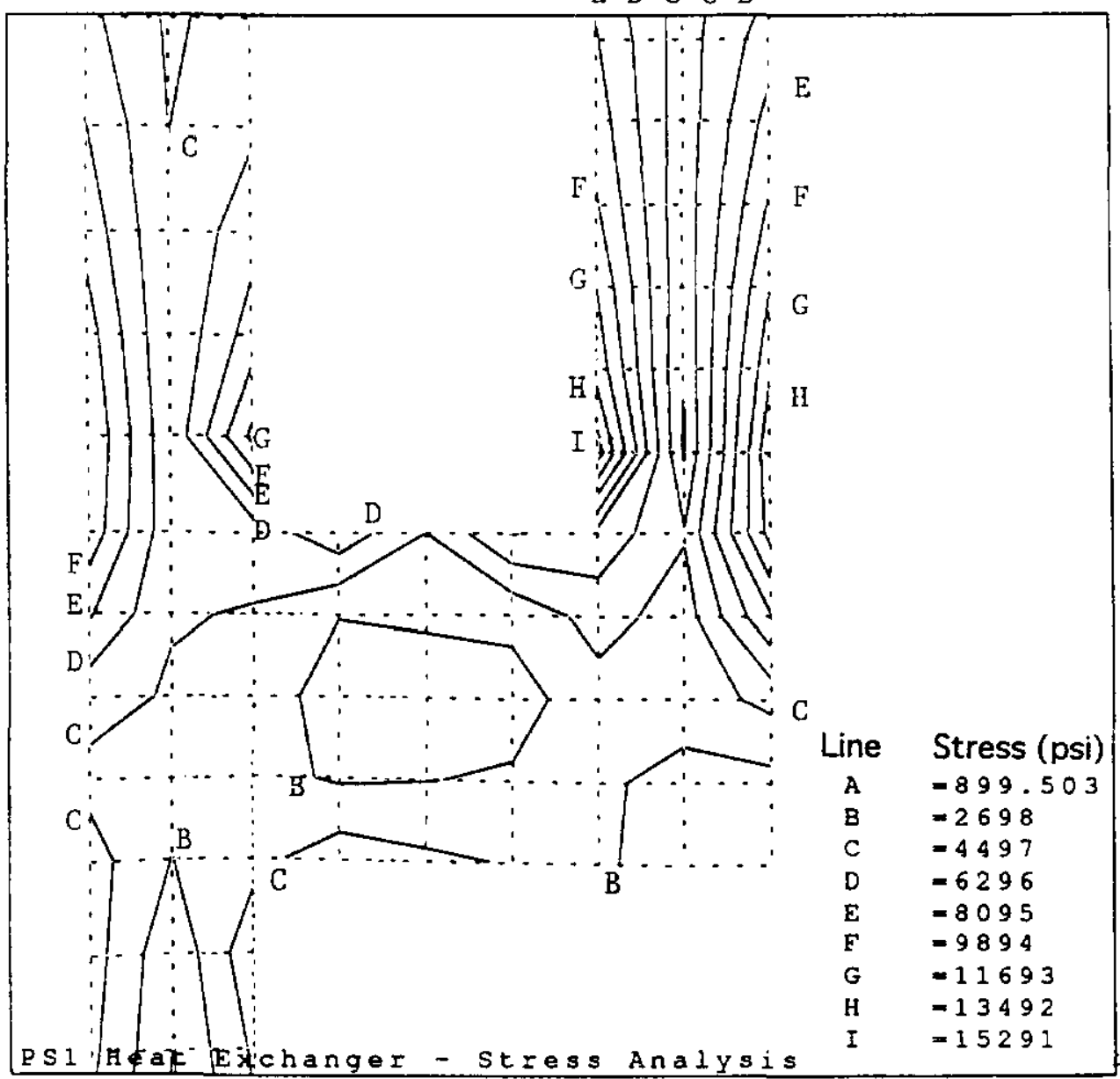

Figure 9. Stress distribution derived from the ANSYS analysis for the modification of the heat exchanger with free convection (maximum-shear criterion).

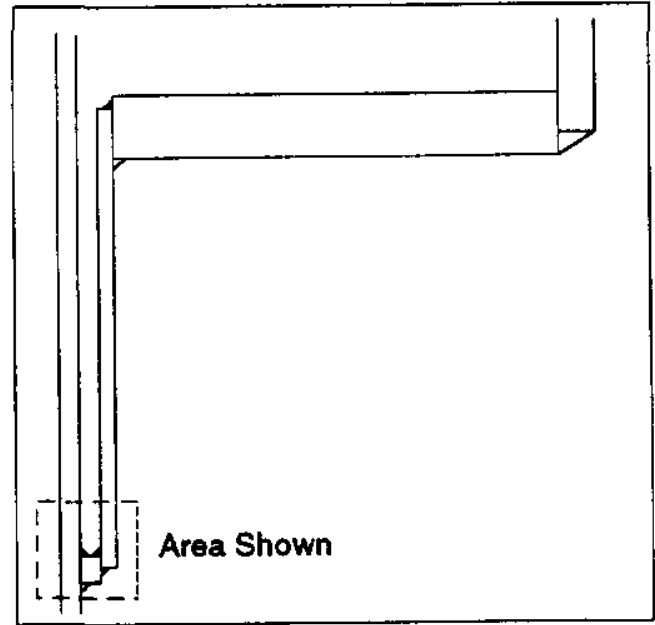




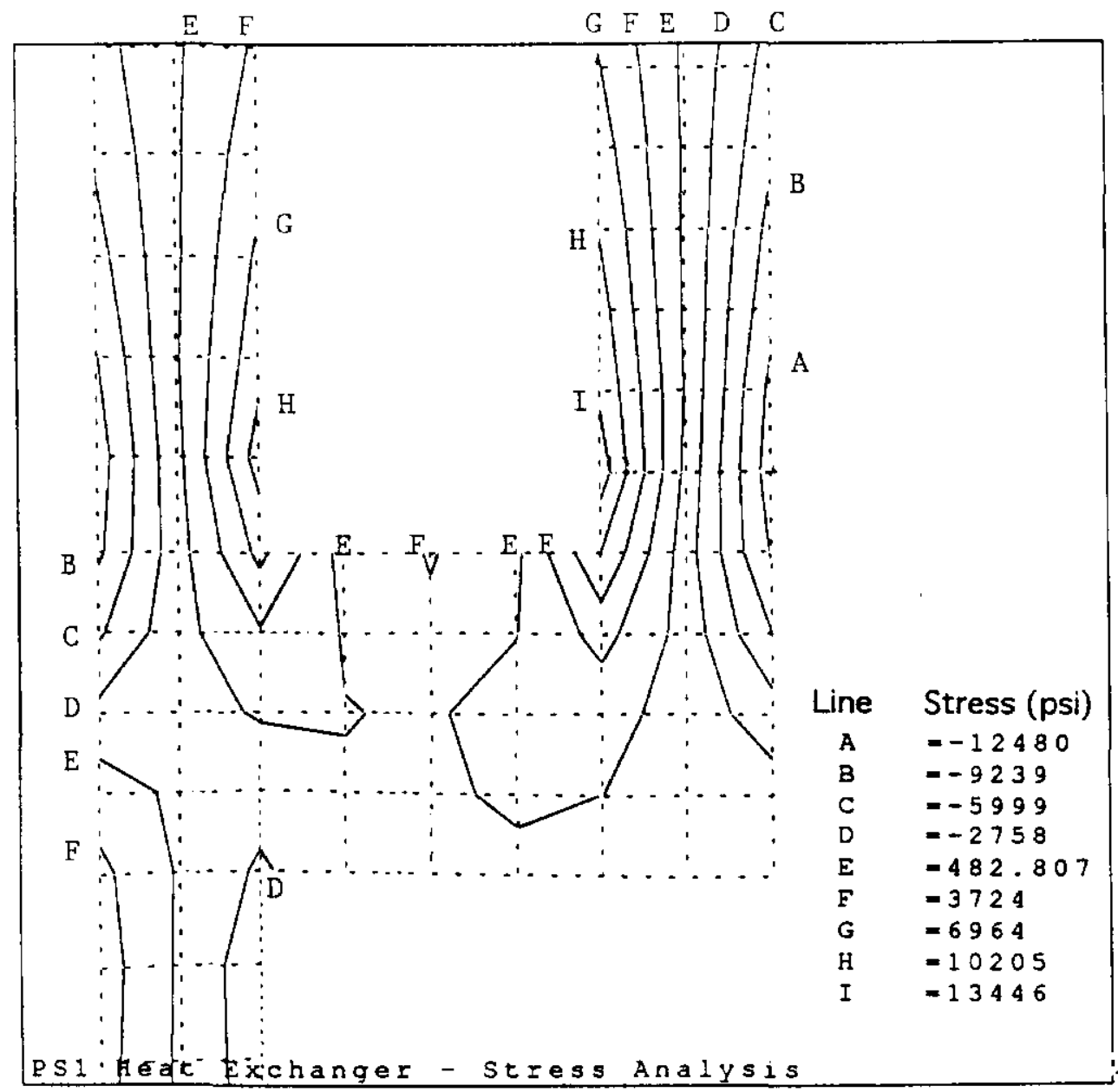

Figure 10. Axial component stresses derived from the ANSYS analysis of the modification to the heat exchanger with free convection.

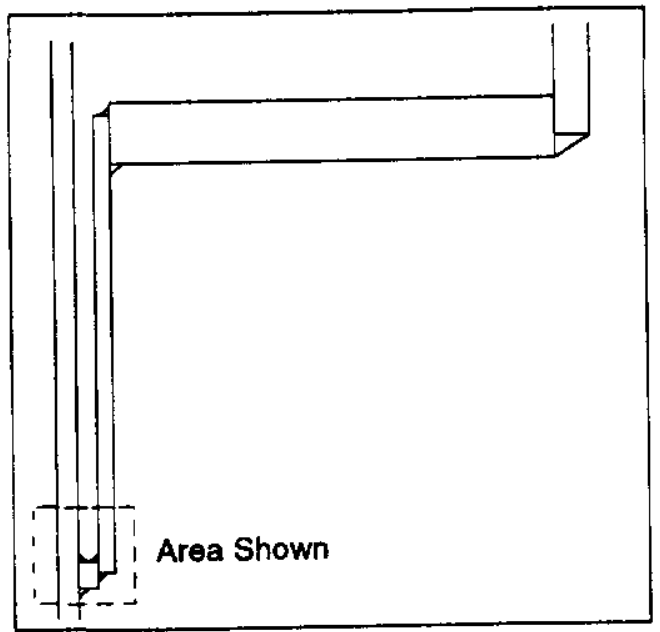




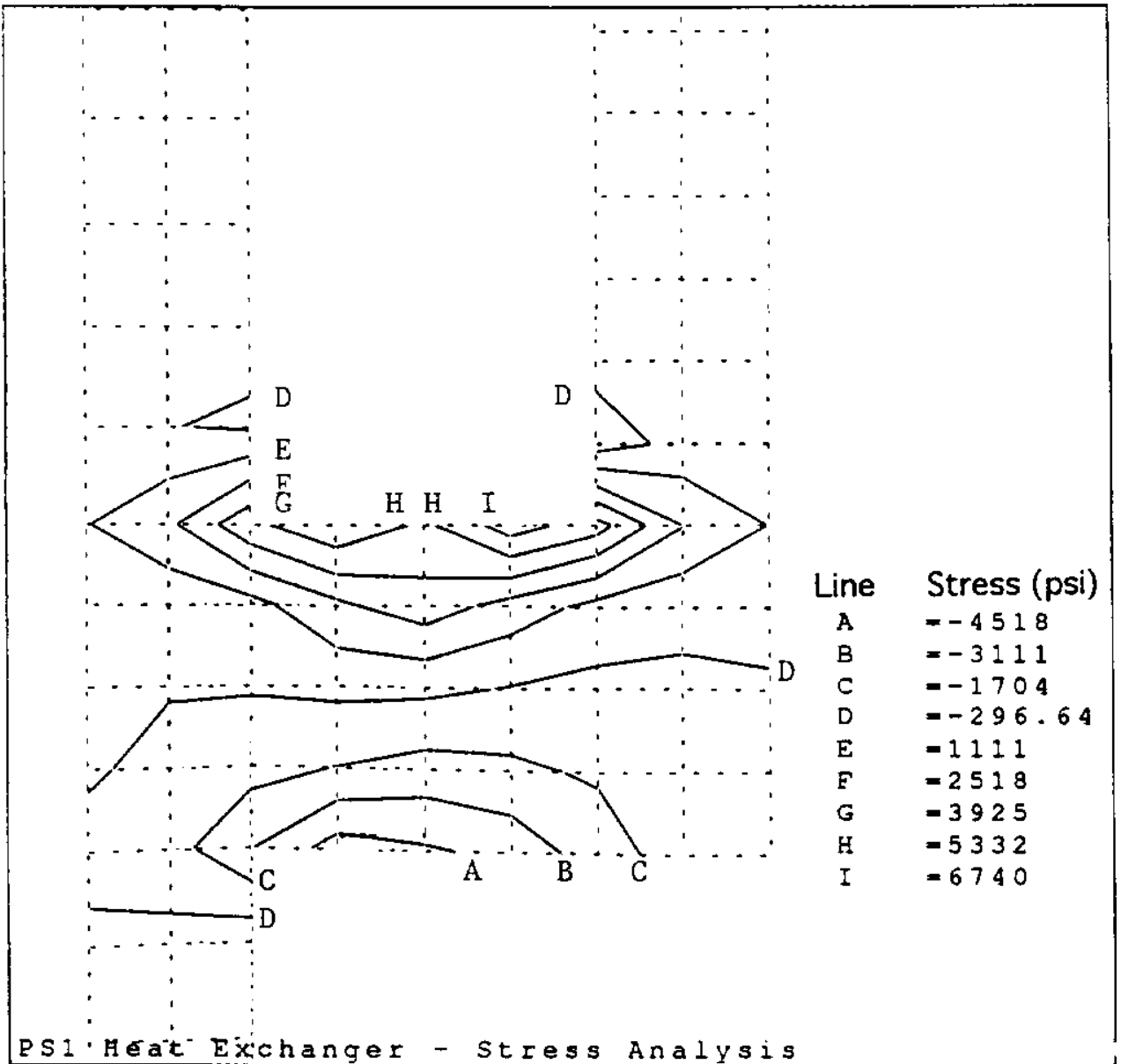

Figure 11. Radial component stresses derived from the ANSYS analysis of the modification to the heat exchanger with free convection.

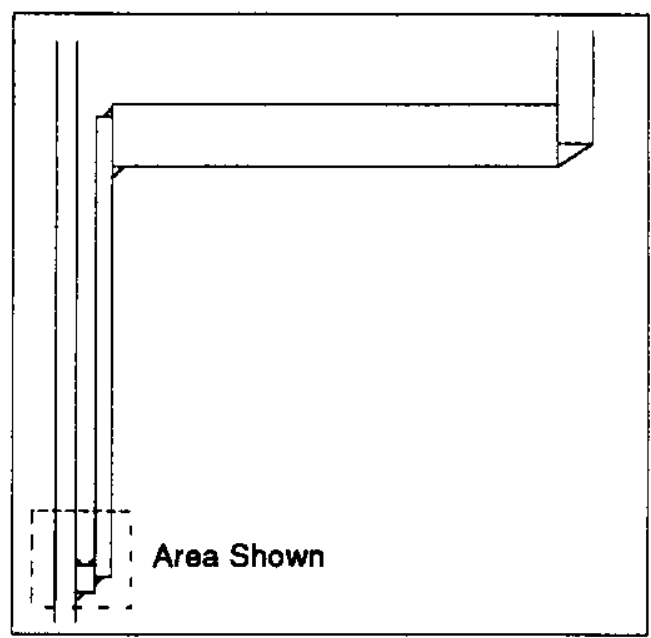




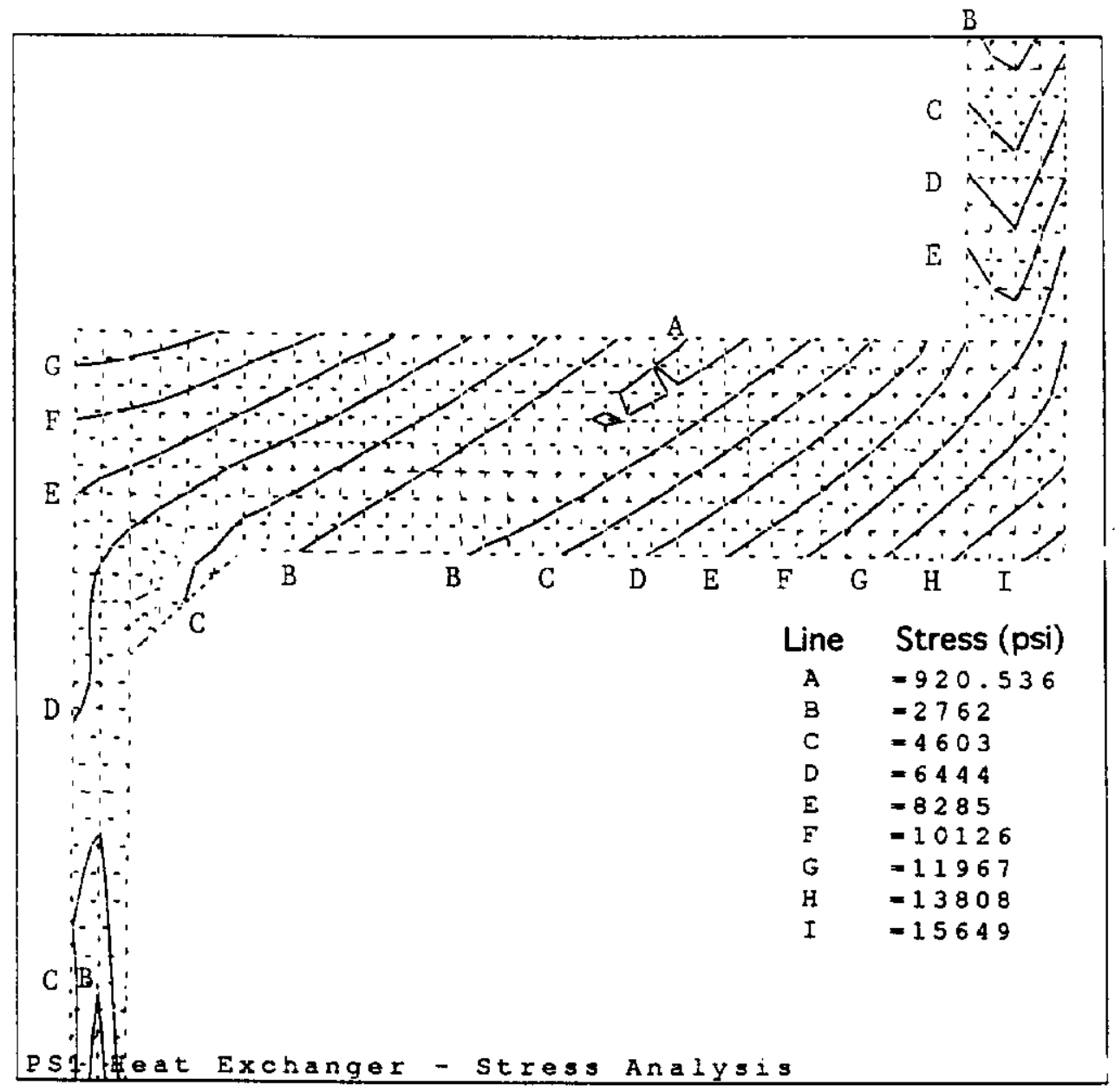

Figure 12. Stress distribution derived from the ANSYS analysis of the modification to the heat exchanger with forced convection (maximum-shear criterion).

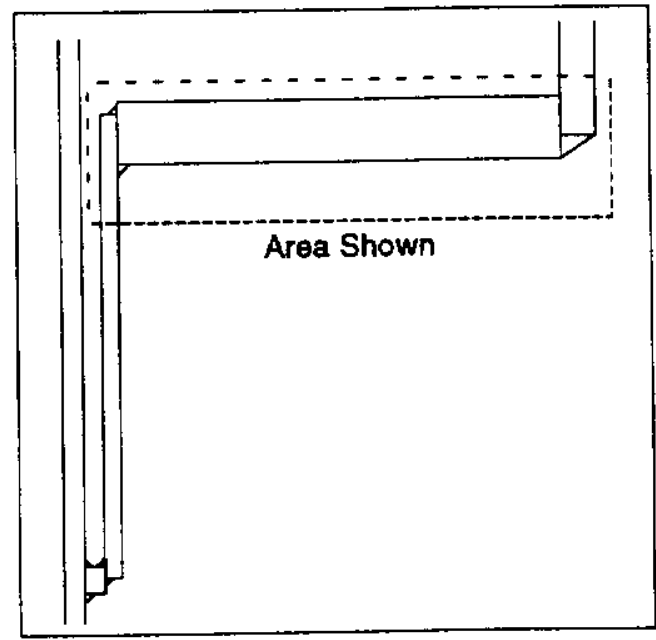




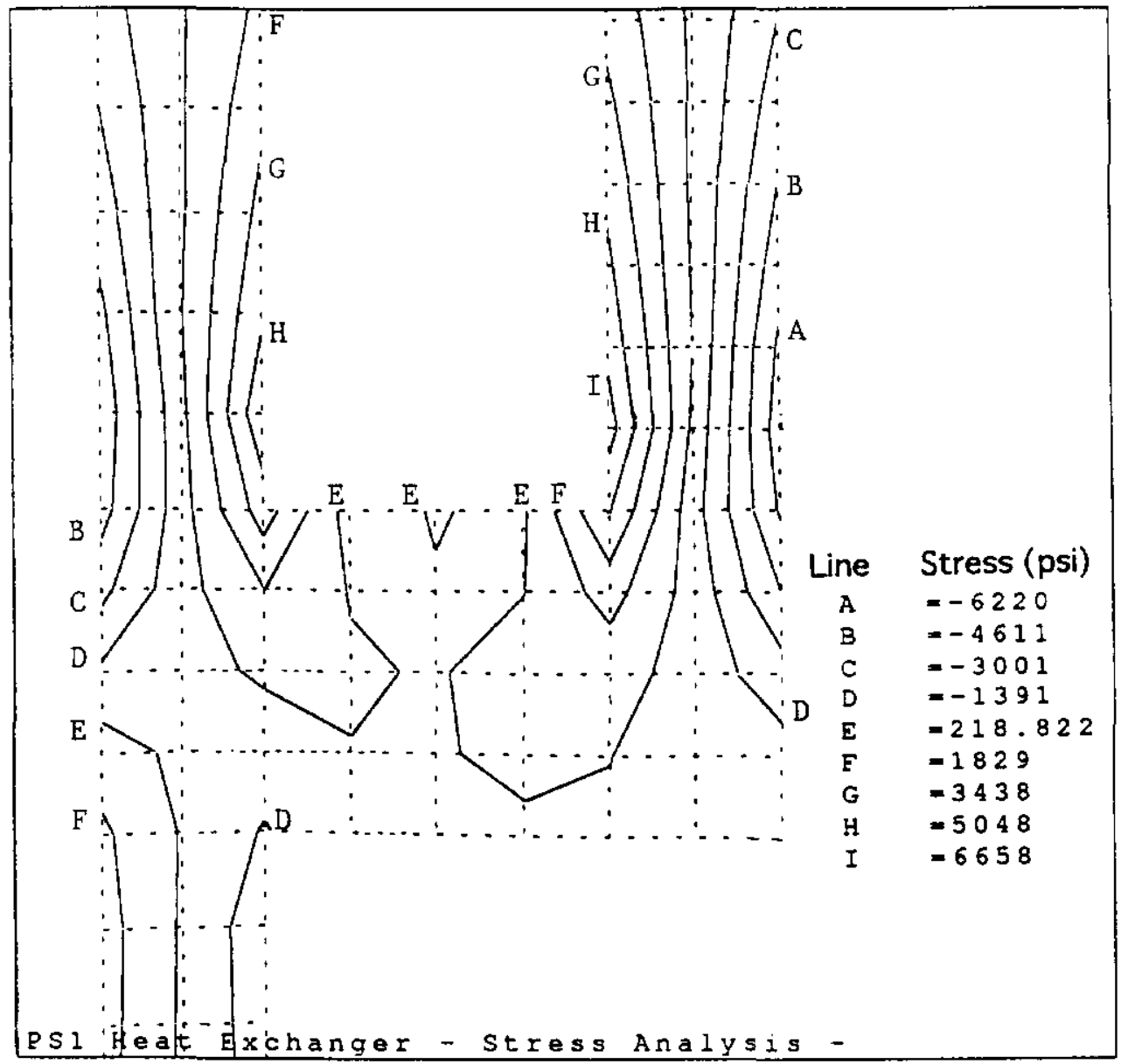

Figure 13. Axial component stresses derived from the ANSYS analysis of the modification to the heat exchanger with forced convection.

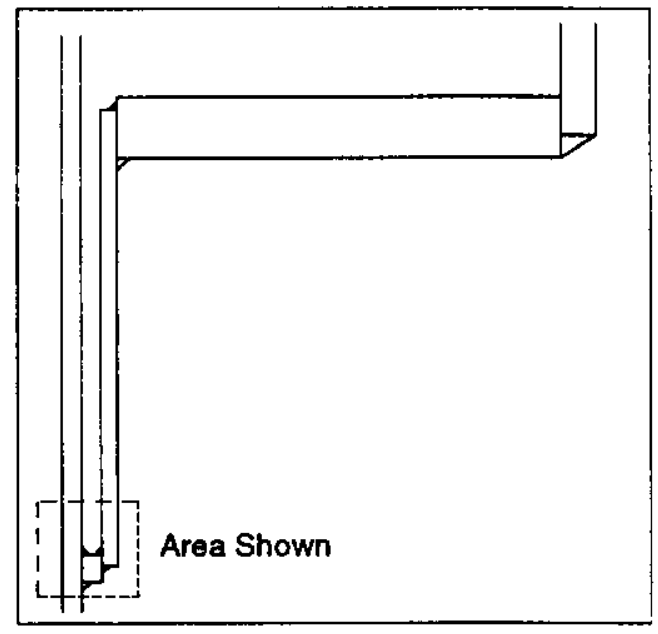




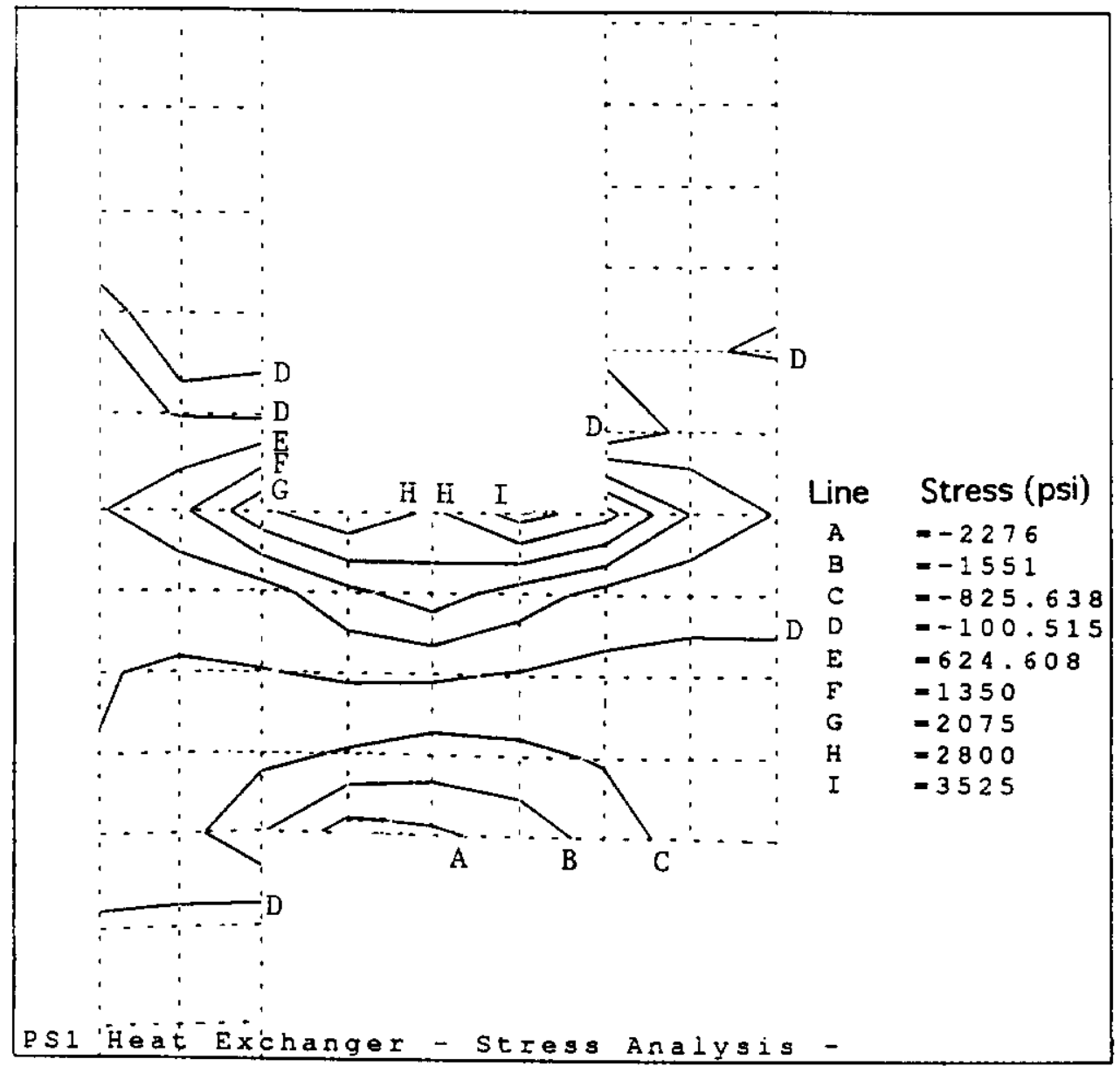

Figure 14. Radial component stresses derived from the ANSYS analysis of the modification to the heat exchanger with forced convection.

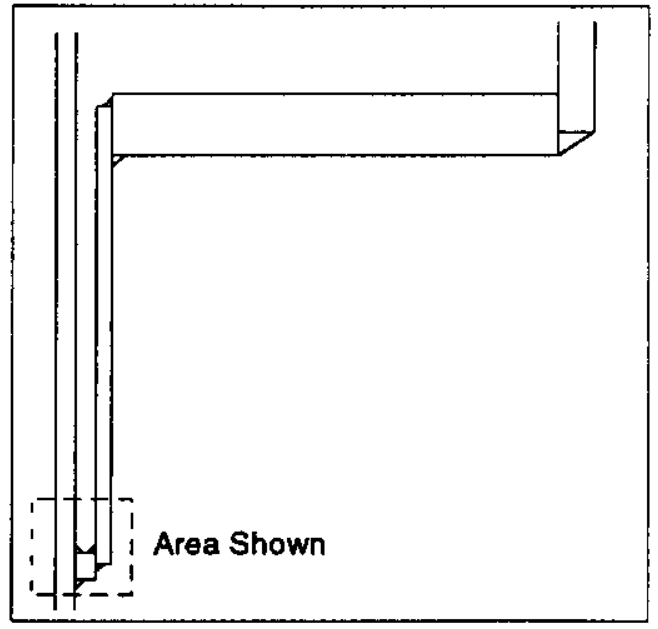

